\title{
The first nation-wide study revealing epidemiologic data and life quality aspects of psoriasis in Romania
}

\author{
ANDREEA NICOLETA BOCA ${ }^{1 *}$, ROXANA FLAVIA ILIES $^{2^{*}}$, STEFAN VESA $^{1}$, RALUCA POP $^{1}$, \\ ALEXANDRU DUMITRU TATARU ${ }^{3}$ and ANCA DANA BUZOIANU ${ }^{1}$
}

\author{
${ }^{1}$ Department of Pharmacology, Toxicology and Clinical Pharmacology, 'Iuliu Hatieganu' University of Medicine \\ and Pharmacy, 400337 Cluj-Napoca; ${ }^{2}$ Department of Medical Genetics, Faculty of Medicine, \\ 'Iuliu Hatieganu' University of Medicine and Pharmacy, 400349 Cluj-Napoca; ${ }^{3}$ Department of Dermatology, \\ 'Iuliu Hatieganu' University of Medicine and Pharmacy, 400006 Cluj-Napoca, Romania
}

Received August 19, 2018; Accepted February 27, 2019

DOI: $10.3892 / e t m .2019 .7652$

\begin{abstract}
Psoriasis is a chronic, immune mediated, inflammatory condition, which primarily affects the patient's skin. It is known to associate a variable array of comorbidities such as cardiovascular, metabolic and psychiatric ones, with an important impact on the patients' quality of life. The purpose of this study is to provide a first image of the prevalence, comorbidities, as well as the social impact of psoriasis in Romania. We devised a questionnaire, and with the aid of general practitioners throughout the country, delivered it to patients seeking medical care in their office. The questionnaire assessed demographic criteria as well as patient-related issues. It was completed in the presence of the general practitioner, and clear written instructions for completion were included. After statistical analysis, the resulting data formed the basis of this study. The reported prevalence of psoriasis in Romania is 5.18\%. Almost half of the subjects who completed the questionnaire stated they knew somebody affected by the disease, yet almost a third believed it is a contagious condition. Cardiovascular and psychiatric comorbidities, as well as negative impact on social interactions were reported by the subjects in the study. These findings indicate the clear need for better quality of life for patients in a social context and increased awareness of the disease. All these could, in turn, help decrease the rate of psoriasis complications in Romania.
\end{abstract}

Correspondence to: Professor Alexandru Dumitru Tataru, Department of Dermatology, 'Iuliu Hatieganu' University of Medicine and Pharmacy, 3 Clinicilor Street, 400006 Cluj-Napoca, Romania E-mail: dr.tataru@yahoo.com

*Contributed equally

Key words: psoriasis, prevalence, epidemiology, quality of life

\section{Introduction}

Psoriasis is an immune-mediated disease (1), with cutaneous and systemic manifestations and substantial negative effects on the patients' quality of life. It showcases a complex etiopathogenesis, occurring through inflammation and epidermal hyperproliferation (2-4). As described in literature, it has a hereditary component, requiring an association of genetic factors such as the involvement of HLA-Cw6-now known as the psoriasis susceptibility locus 1 (PSORS1) (2), as well as polymorphic variants of interleukins $(5,6)$ and environmental triggers such as cigarette smoke $(7,8)$, stress (9), western type diets (6-8) to become manifest.

A significant amount of scientific interest has been pointed in the direction of comorbidities associated with psoriasis. Some of these, such as cardiovascular conditions (10-13), psoriatic arthritis, metabolic syndrome (10), other autoimmune conditions (14) and psychiatric conditions (anxiety and depression) $(9,15)$ are well-documented. In addition, a number of studies have unveiled correlations (16) with liver fibrosis, sleep disorders (17), ophthalmic conditions, osteoporosis, irritable bowel syndrome, kidney disease, erectile dysfunction (18) and an increased risk of developing neoplasia (19).

Literature reports a highly variable incidence of psoriasis throughout various countries, with numbers ranging from 0 to $11 \%$ of an area's population $(20,21)$. Despite the impressive amount of literature on the matter, issues such as comorbidities and quality of life are rarely addressed in a full and cohesive manner $(22,23)$.

The purpose of this study was to provide the first reported aspects of psoriasis in Romania, with an emphasis on prevalence, quality of life and comorbidities. The obtained information might help increase the quality of life of these patients, address complications and lower the long-term economical burden of managing this condition $(24,25)$.

\section{Materials and methods}

This is a questionnaire-based study with sample populations coming from all regions of the country, in a representative distribution. The questionnaire (available upon request) was 
developed based on the model of the questionnaire used by Saraceno et al (20). This material was sent to general practitioners around the country, accompanied by an explanatory letter with instructions for the completion of the questions (available upon request).

The project was approved by the Ethics Committee of 'Iuliu Hatieganu' University of Medicine and Pharmacy (Cluj-Napoca, Romania), under the terms of the Helsinki agreement, and an informed written consent was provided by all the patients included in this study. For minors, the questionnaires were filled out by their legal representatives.

In order to reach a significant statistical value, the required sample size of our study was calculated at 2,200 subjects; in order to reach this number, 2,500 questionnaires with accompanying letters were sent out to all Romanian counties, proportional to the population number inhabiting each area.

The questionnaires, printed on A4 sheets of paper, contain 15 items as follows: the first 9 questions address general demographic data, the 10th question relates to smoking, while the following 5 questions are focused on the disease. Each general practitioner received an envelope with 12 questionnaires, accompanied by a letter which outlined the general requirements for the correct completion of this stage. The general practitioners should select 12 patients at random, with or without a diagnosis of psoriasis, to include patients of both sexes and all age groups, to administer 6 questionnaires in the days where their service was open in the morning and the other 6 were to be made available for patients requesting consultation in the afternoon.

After receiving the completed questionnaires, we analyzed the data from 2,240 well-completed questionnaires and transformed the obtained data in a Microsoft Excel spreadsheet (Microsoft, Redmond, VA, USA). For the statistical analysis SPSS statistical software (version 2.0; SPSS, Inc., Chicago, IL, USA) was used. The variables were considered as nominal or binary and the required frequencies were calculated. For the univariate analysis of the nominal variables the Pearson's Chi-square test was used. P-value $<0.05$ was considered to indicate a statistically significant difference.

\section{Results}

The study had a start-off maximum participant number of 2,500 , equivalent to the number of questionnaires sent in the entire country. Due to improper completion or non-returning of these materials, the study lost 260 potential candidates, leading to a final number of 2,240 eligible participants. The sex distribution after the random completion of the questionnaires was 975 male subjects and 1,265 female subjects, with ages ranging from 2 years to 92 years, with an average of 47 years of age.

The prevalence of psoriasis in Romania varied significantly between regions, with a prevalence of $0.65 \%$ in Banat and $7.61 \%$ in Oltenia $(\mathrm{P}=0.004)$. The overall prevalence of psoriasis in Romania is $5.18 \%$. The complete percentages per region are represented in Table I.

The general information revealed demographic data on the participants in this study, as well as potential risk factors. The complete analysis of these findings is detailed in Table II; the only statistically significant correlation was made with age:
Table I. Prevalence of psoriasis in all regions of Romania.

\begin{tabular}{lcccc}
\hline Regions & $\begin{array}{c}\text { Subjects } \\
\text { suffering } \\
\text { from } \\
\text { psoriasis }\end{array}$ & $\begin{array}{c}\text { Subjects } \\
\text { with } \\
\text { no psoriasis } \\
\text { diagnosis }\end{array}$ & $\begin{array}{c}\text { Total } \\
\text { subjects }\end{array}$ & $\begin{array}{c}\text { Reported } \\
\text { prevalence }\end{array}$ \\
\hline Banat & 1 & 153 & 154 & 0.65 \\
Bucovina & 4 & 91 & 95 & 4.21 \\
Crișana & 8 & 121 & 129 & 6.20 \\
Dobrogea & 5 & 126 & 131 & 3.82 \\
Maramures & 6 & 86 & 92 & 6.52 \\
Moldova & 15 & 374 & 389 & 3.86 \\
Muntenia & 31 & 544 & 575 & 5.39 \\
Oltenia & 21 & 255 & 276 & 7.61 \\
Transilvania & 25 & 374 & 399 & 6.27 \\
Total & 116 & 2,124 & 2,240 & 5.18 \\
\hline
\end{tabular}

Table II. Demographic parameters, potential exposures and risk factors.

\begin{tabular}{|c|c|c|c|c|c|}
\hline Variables & $\begin{array}{l}\text { Patients } \\
\text { with } \\
\text { psoriasis }\end{array}$ & $\begin{array}{l}\text { Patients } \\
\text { with } \\
\text { psoriasis } \\
(\%)\end{array}$ & $\begin{array}{c}\text { Patients } \\
\text { without } \\
\text { psoriasis }\end{array}$ & $\begin{array}{c}\text { Patients } \\
\text { without } \\
\text { psoriasis } \\
(\%)\end{array}$ & P-value \\
\hline \multicolumn{6}{|l|}{ Regions } \\
\hline Urban region & 99 & 86.1 & 1,911 & 89.9 & 0.244 \\
\hline Rural region & 16 & 13.9 & 214 & 10.1 & \\
\hline Age (years) & 57 & & 47 & & 0.001 \\
\hline \multicolumn{6}{|l|}{ Sex } \\
\hline Male & 54 & 47.0 & 921 & 43.3 & 0.506 \\
\hline Female & 61 & 53.0 & 1,204 & 56.7 & \\
\hline \multicolumn{6}{|l|}{ BMI $\left(\mathrm{kg} / \mathrm{m}^{2}\right)$} \\
\hline$<30$ & 85 & 73.9 & 1,637 & 77.0 & 0.509 \\
\hline$\geq 30$ & 30 & 26.1 & 488 & 23.0 & \\
\hline \multicolumn{6}{|l|}{ Smoking status } \\
\hline Smoker & 63 & 54.8 & 1,274 & 59.9 & 0.321 \\
\hline Non-smoker & 52 & 45.2 & 852 & 40.1 & \\
\hline
\end{tabular}

the average age of patients suffering from psoriasis was above the general population (57 vs. 47 years old; $\mathrm{P}<0.001$ ).

Respondents $(31.1 \%)$ declared that they knew someone suffering from psoriasis; in $9.5 \%$ of the cases, the person in question was related to the respondent, $41.2 \%$ of the population consider themselves knowledgeable about this condition, however $20.4 \%$ of these consider psoriasis a contagious disease. Of the respondents $28.8 \%$ declared assuredly knowing about psoriasis, out of which $7.6 \%$ consider it a contagious condition. Approximately a third (30\%) of the Romanian population have no knowledge of the existence of this condition; when presented with a typical lesion, $44.8 \%$ of them believe it is a contagious condition.

The aspects of life affected by psoriasis are elaborated in Table III. It is significant to note that $86.95 \%$ of patients 
Table III. Aspects of social interactions affected by psoriasis.

\begin{tabular}{lcc}
\hline Psoriasis affects & $\begin{array}{c}\text { Patients with } \\
\text { psoriasis }\end{array}$ & $(\%)$ \\
\hline Relationship with partner or close family & 40 & 34.8 \\
Relationship with entire family and friends & 41 & 35.7 \\
Interactions at the workplace/with superiors & 53 & 46.1 \\
Social comfort in public places & 79 & 68.7 \\
At least one of the above aspects & 100 & 86.95 \\
All of the above & 22 & 19.1 \\
\hline
\end{tabular}

Table IV. Comorbidities in patients with psoriasis.

\begin{tabular}{|c|c|c|c|c|c|}
\hline Comorbidities & $\begin{array}{c}\text { With } \\
\text { psoriasis }\end{array}$ & $\begin{array}{l}\text { Patients } \\
\text { with } \\
\text { psoriasis } \\
(\%)\end{array}$ & $\begin{array}{l}\text { Without } \\
\text { psoriasis }\end{array}$ & $\begin{array}{c}\text { Patients } \\
\text { without } \\
\text { psoriasis } \\
\quad(\%)\end{array}$ & $\mathrm{P}$-value \\
\hline Cardiovascular & 60 & 52.2 & 688 & 32.4 & 0.001 \\
\hline Psychiatric & 33 & 28.7 & 209 & 9.8 & 0.001 \\
\hline Diabetes mellitus & 20 & 17.4 & 261 & 12.3 & 0.143 \\
\hline Digestive & 32 & 27.8 & 487 & 22.9 & 0.271 \\
\hline
\end{tabular}

suffering from psoriasis mention that at least one social aspect of their lives is affected by this condition; furthermore, around a fifth of patients $(19.1 \%)$ state that this condition affects all the questioned aspects of social interactions. Our study found that $90.8 \%$ of patients suffering from psoriasis are not married, significantly more than the $81.3 \%$ of subjects not affected by the disease.

Another relevant aspect revealed by the study assesses comorbidities. It reports $52.2 \%$ of patients suffering from psoriasis also suffer from a cardiac condition versus only $32.4 \%$ of the non-affected population $(\mathrm{P}<0.001)$. When referring to psychiatric comorbidities, the percentages are $28.7 \%$ for patients with psoriasis vs. 9.8\% for the non-affected population $(\mathrm{P}<0.001)$. Other factors analyzed have been noted to appear more frequently in patients with psoriasis, however these findings did not achieve statistical significant difference (Table IV).

\section{Discussion}

Our study revealed a prevalence of $5.18 \%$ of psoriasis in Romania, placing our country on the higher end of Europe's average of $2-8.15 \%$ (26). However, this percentage is not homogeneous throughout the regions of Romania; as such, the explanation may reside in diverse environmental exposures, climate, or genetic factors. For instance, Dobrogea reported a relatively low prevalence of psoriasis, which could be attributed to this region's access to the sea, beaches and the overall warmer, sunnier climate. Climate, and especially ultraviolet exposure is a factor frequently discussed by psoriasis studies $(20,27)$.

The present study reports that most patients $(\sim 70 \%)$ are uncomfortable in social situations due to their illness, with $\sim 40 \%$ reporting that their family, workplace, or social interactions are affected negatively by their condition. Literature reports a complex interplay between psychological well-being and skin condition, through psychoneuroimmune mechanisms. The social aspect of a patients' life is a predictor for overall psychological well-being and our results strongly suggest that psoriasis affects negatively the patients' social life. This leads to a vicious circle, enforced by two components: lowered quality of life through stigma and increased risk of mental illness as well as the threat for more skin damage through increased concentrations of stress-induced mediators (28-30).

Findings of our study indicate that the level of basic medical education in the general population is low. This promotes the spread of pseudoscience and myths surrounding psoriasis, leading to an unsuitable psychological environment for people affected by this condition. Education of the patients' regarding their disease, and of the general population regarding the noncontagious nature of it, would be a positive predictor for illness acceptance. This factor has been associated with an overall improved mental condition of the patients (30).

The strong correlation between psoriasis and psychiatric comorbidities and the reports from the patients themselves put forth the need to further inform the general population about this condition and to offer early support to patients struggling to cope with their condition. There is a quantifiable link between shame over the disease and stigma (31), with stigma being an important predictor for lowered quality of life (30).

The reported correlation with cardiac diseases closely aligns with the current literature on the matter. Correia and Torres (32), Husni (16), Raposo and Torres (33) also report links between psoriasis and cardiometabolic conditions. All these reinforce the need to raise awareness and routinely screen psoriasis patients for cardiac as well as psychiatric conditions.

This study poses its share of limitations. It is a sample based study and it is hard to confirm the objective nature of the questionnaires, since they are based on what the subjects report. Some of the subjects were very young ( 2 years old being the extreme)-in this case, the answers were provided through their legal guardian. No dermatological consult was requested in order to confirm the diagnosis. Alongside, it is possible that more patients diagnosed with psoriasis suffer from diabetes mellitus, cardiac conditions, psychiatric conditions or digestive issues but are simply unaware of these.

Far from being a definitive statistic on psoriasis in Romania, our study provides the first compiled information of this nature in our country, providing grounds and justification for further studies in order to confirm, or add to our findings.

Our data aim to bring forth and shed light on the significant number of patients with a decreased quality of life due to this condition, and bridge the gap between our medical system and the patient in need of care.

It is remarked in the available literature that one of the barriers to guideline-compliant psoriasis care (34) is physician-related, namely the incomplete knowledge of adapted therapeutic options, comorbidities and life quality impact of this disease. The incomplete managed situation of psoriasis is a real burden to the patients, as well as an economical strain for the healthcare system (35).

In conclusion, Romania is one of the European countries that presents a relatively high prevalence of psoriasis, asso- 
ciated with poor education on the subject. Psoriatic patients, regardless of location, should benefit from screening and early intervention in comorbidities. Psychological and cardiac screening programs would bring benefit to the quality of life of these patients, and also to the national health system.

While steps are being taken to facilitate an optimal management of psoriatic patients in Romania, for example through the elaboration of a National Register for Patients Suffering from Psoriasis, there is still a need for targeted psychological care in these patients. The framework for this important next step already exists, through the National Register. The data reported by this present study supports further steps in the direction of improving the management of psoriasis, by various measures such as educational programs.

\section{Acknowledgements}

Not applicable.

\section{Funding}

No funding was received.

\section{Availability of data and materials}

The data are available on request to the corresponding author.

\section{Authors' contributions}

ANB, RFI and RP were responsible for the design of the study, the questionnaires, the acquisition of data and contributed to the interpretation of the results. ANB and RFI contributed to the writing of the manuscript. SV was in charge of the statistical analysis. ADB and ADT took part in designing the study and supervised the entire process and guided us through the process, they had full access to the data in the study and take responsibility for the integrity and accuracy of the data analysis. All authors read and approved the final version.

\section{Ethics approval and consent to participate}

The present study was approved by the Ethics Committee of 'Iuliu Hatieganu' University of Medicine and Pharmacy (Cluj-Napoca, Romania), and an informed written consent was provided by all the patients included in this study.

\section{Patient consent for publication}

Not applicable.

\section{Competing interests}

The authors declare that they have no competing interests.

\section{References}

1. Benson MM and Frishman WH: The heartbreak of psoriasis: A review of cardiovascular risk in patients with psoriasis. Cardiol Rev 23: 312-316, 2015.

2. Boehncke WH: Etiology and pathogenesis of psoriasis. Rheum Dis Clin North Am 41: 665-675, 2015.
3. Batani A, Brănisteanu DE, Ilie MA, Boda D, Ianosi S, Ianosi G and Caruntu C: Assessment of dermal papillary and microvascular parameters in psoriasis vulgaris using in vivo reflectance confocal microscopy. Exp Ther Med 15: 1241-1246, 2018.

4. Căruntu C, Boda D, Căruntu A, Rotaru M, Baderca F and Zurac S: In vivo imaging techniques for psoriatic lesions. Rom J Morphol Embryol 55 (Suppl 3): 1191-1196, 2014.

5. Olteanu R, Constantin M, Zota A, Dorobanțu D, Constantin T, Serban ED, Bălănescu P, Mihele D and Solovăstru LG: Original clinical experience and approach to treatment study with interleukine 12/23 inhibitor in moderate-to-severe psoriasis patients. Farmacia 64: 2-5, 2016.

6. Boca AN, Patronea A, Vesa Ş, Lazăr D, Costanzo A and Buzoianu AD: Dissecting genes, looking for psoriasis: An IL-6 gene polymorphism. Basic Res Clujul Med 86: 9-11, 2013.

7. Richer V, Roubille C, Fleming P, Starnino T, McCourt C, McFarlane A, Siu S, Kraft J, Lynde C, Pope JE, et al: Psoriasis and smoking: A systematic literature review and meta-analysis with qualitative analysis of effect of smoking on psoriasis severity. J Cutan Med Surg 20: 221-227, 2016.

8. Li X, Kong L, Li F, Chen C, Xu R, Wang H, Peng S, Zhou M and Li B: Association between psoriasis and chronic obstructive pulmonary disease: A systematic review and meta-analysis. PLoS One 10: e0145221, 2015.

9. Connor CJ, Liu V and Fiedorowicz JG: Exploring the physiological link between psoriasis and mood disorders. Dermatol Res Pract 2015: 409637, 2015.

10. Castaldo G, Galdo G, Rotondi Aufiero F and Cereda E: Very low-calorie ketogenic diet may allow restoring response to systemic therapy in relapsing plaque psoriasis. Obes Res Clin Pract 10: 348-352 2016.

11. Wong AP, Kalinovsky T, Niedzwiecki A and Rath M: Efficacy of nutritional treatment in patients with psoriasis: A case report. Exp Ther Med 10: 1071-1073, 2015.

12. Barrea L, Macchia PE, Tarantino G, Di Somma C, Pane E, Balato N, Napolitano M, Colao A and Savastano S: Nutrition: A key environmental dietary factor in clinical severity and cardiometabolic risk in psoriatic male patients evaluated by 7-day food-frequency questionnaire. J Transl Med 13: 303, 2015.

13. Irimie M, Oantă A, Irimie CA, Fekete LG, Minea DI and Pascu A: Cardiovascular risk factors in patients with chronic plaque psoriasis: A case-control study on the Brasov County population. Acta Dermatovenerol Croat 23: 28-35, 2015.

14. Cabrijan L and Kehler T: Association of psoriasis with other diseases. Acta Med Croatica 69: 59-63, 2015.

15. Cohen BE, Martires KJ and Ho RS: Psoriasis and the risk of depression in the US population: National Health and Nutrition Examination Survey 2009-2012. JAMA Dermatol 152: 73-79, 2016.

16. Husni ME: Comorbidities in psoriatic arthritis. Rheum Dis Clin North Am 41: 677-698, 2015.

17. Gupta MA, Simpson FC and Gupta AK: Psoriasis and sleep disorders: A systematic review. Sleep Med Rev 29: 63-75, 2016.

18. Korman AM, Hill D, Alikhan A and Feldman SR: Impact and management of depression in psoriasis patients. Expert Opin Pharmacother 17: 147-152, 2016.

19. Li WQ, Han J, Cho E, Wu S, Dai H, Weinstock MA and Qureshi AA: Personal history of psoriasis and risk of incident cancer among women: A population-based cohort study. Br J Dermatol 174: 1108-1111, 2016.

20. Saraceno R, Mannheimer R and Chimenti S: Regional distribution of psoriasis in Italy. J Eur Acad Dermatol Venereol 22: 324-329, 2008.

21. Rachakonda TD, Schupp CW and Armstrong AW: Psoriasis prevalence among adults in the United States. J Am Acad Dermatol 70: 512-516, 2014.

22. Cobo-Ibáñez T, Villaverde V, Seoane-Mato D, MuñozFernández S, Guerra M, Del Campo PD and Cañete JD: Multidisciplinary dermatology-rheumatology management for patients with moderate-to-severe psoriasis and psoriatic arthritis: A systematic review. Rheumatol Int 36: 221-229, 2016.

23. Khawaja AR, Bokhari SMA, Tariq R, Atif S, Muhammad H, Faisal Q and Jafferany M: Disease severity, quality of life, and psychiatric morbidity in patients with psoriasis with reference to sociodemographic, lifestyle, and clinical variables: A prospective, cross-sectional study from Lahore, Pakistan. Prim Care Companion CNS Disord 17: doi: 10.4088/PCC.14m01629, 2015.

24. Köhn FM, Schuppe HC and Beier KM: Dermatological diseases and sexuality: How to proceed? Hautarzt 66: 907-912, 2015 (In German). 
25. Spelman L, Su JC, Fernandez-Peñas P, Varigos GA, Cooper AJ, Baker CS, Lee M, Ring JM and Thirunavukkarasu K: Frequency of undiagnosed psoriatic arthritis among psoriasis patients in Australian dermatology practice. J Eur Acad Dermatol Venereol 29: 2184-2191, 2015.

26. Parisi R, Symmons DP, Griffiths CE and Ashcroft DM Identification and Management of Psoriasis and Associated ComorbidiTy (IMPACT) project team: Global epidemiology of psoriasis: A systematic review of incidence and prevalence. J Invest Dermatol 133: 377-385, 2013.

27. Jacobson CC, Kumar S and Kimball AB: Latitude and psoriasis prevalence. J Am Acad Dermatol 65: 870-873, 2011

28. Hall JM, Cruser D, Podawiltz A, Mummert DI, Jones H and Mummert ME: Psychological stress and the cutaneous immune response: Roles of the HPA axis and the sympathetic nervous system in atopic dermatitis and psoriasis. Dermatol Res Pract 2012: 403908, 2012.

29. Shenefelt PD: Psychological interventions in the management of common skin conditions. Psychol Res Behav Manag 3: 51-63, 2010 .
30. Kostyła M, Tabała K and Kocur J: Illness acceptance degree versus intensity of psychopathological symptoms in patients with psoriasis. Postepy Dermatol Alergol 30: 134-139, 2013.

31. Rzepa T, Jakubowicz O, Witmanowski H and Zaba R: Diseaseinduced level of shame in patients with acne, psoriasis and syphilis. Postepy Dermatol Alergol 30: 233-236, 2013.

32. Correia B and Torres T: Obesity: A key component of psoriasis. Acta Biomed 86: 121-129, 2015.

33. Raposo I and Torres T: Psoriasis strikes back! Epicardial adipose tissue: Another contributor to the higher cardiovascular risk in psoriasis. Rev Port Cardiol 34: 613-616, 2015.

34. Eissing L, Radtke MA, Zander N and Augustin M: Barriers to guideline-compliant psoriasis care: Analyses and concepts. J Eur Acad Dermatol Venereol 30: 569-575, 2015.

35. Vietri J, Tian H, Gabriel S, Balp M, Khalil S and Zuberbier T: Economic burden of chronic spontaneous urticaria and psoriasis: Patients perspective from Europe. Value Health 18: A424-A425, 2015. 